\title{
El agua: naturaleza y cultura en la Sierra de Aracena y Picos de Aroche
}

Gema Carrera Díaz. Centro de Documentación del IAPH. Antonio Fajardo. Instituto de Cartografía de Andalucía

Los caminos trazados

al agua territorializan

un espacio cultural

antes que natural
El territorio comprendido entre los límites administrativos de la provincia de Badajoz al norte, la frontera con Portugal al oeste, la comarca cultural del Andévalo al sur y las tierras sevillanas de Sierra Morena al este, compone una extensa comarca con 29 municipios y algo más de 3000 kilómetros cuadrados, poblado por 40000 habitantes. Se trata de una unidad territorial con una personalidad definida que, sin embargo, no tiene una denominación aceptada por todos: Sierra de Aracena o Sierra de Huelva. La creación del Parque Natural de Sierra de Aracena y Picos de Aroche ha dado una nueva identidad a la comarca, pese a que éste sólo ocupa algo más de la mitad de su superficie.

La Sierra de Aracena y Picos de Aroche, física y territorialmente, constituye la sección más occidental de Sierra Morena. Este espacio forma parte del reborde meridional de la Meseta, plegado por la orogenia herciniana y suavizado por la erosión de millones de años. Como el resto de Sierra Morena, se ve fragmentado por cursos de agua de dirección mayoritaria noroeste-sureste cuya escasa longitud para el desnivel que han de salvar le proporcionan alta torrencialidad y poder erosivo, sobre todo comparativamente a los afluentes que el Guadalquivir recibe por su margen izquierda. Las formaciones vegetales de este ámbito tienen su continuidad, con peculiaridades, en las sierras de Sevilla, Córdoba y Jaén, y la figura del espacio protegido es compartida por estas últimas: son los Parques Naturales de la Sierra Norte de Sevilla, Hornachuelos, Cardeña y Montoro y Andújar.

Las particulares condiciones climáticas que le confiere su localización a Poniente la benefician con abundancia de precipitaciones por los frentes oceánicos que otorgan a esta comarca una personalidad propia respecto al conjunto de Sierra Morena. Estas diferencias espaciales se van a reflejar en la vegetación dominante, ya que la comarca alberga especies más exigentes en condiciones de humedad y frío, como los castañares, alcornocales y ejemplares dispersos de quejigos y melojos, mientras en las partes bajas predomina la encina.

La red hidrográfica superficial es la principal responsable del modelado del relieve, debido a la antigüedad de los materiales, dando como resultado formas acolinadas en donde la acción erosiva de los cursos de agua ha segmentado el relieve en valles encajados y, sólo puntualmente, origina una topografía escarpada. 


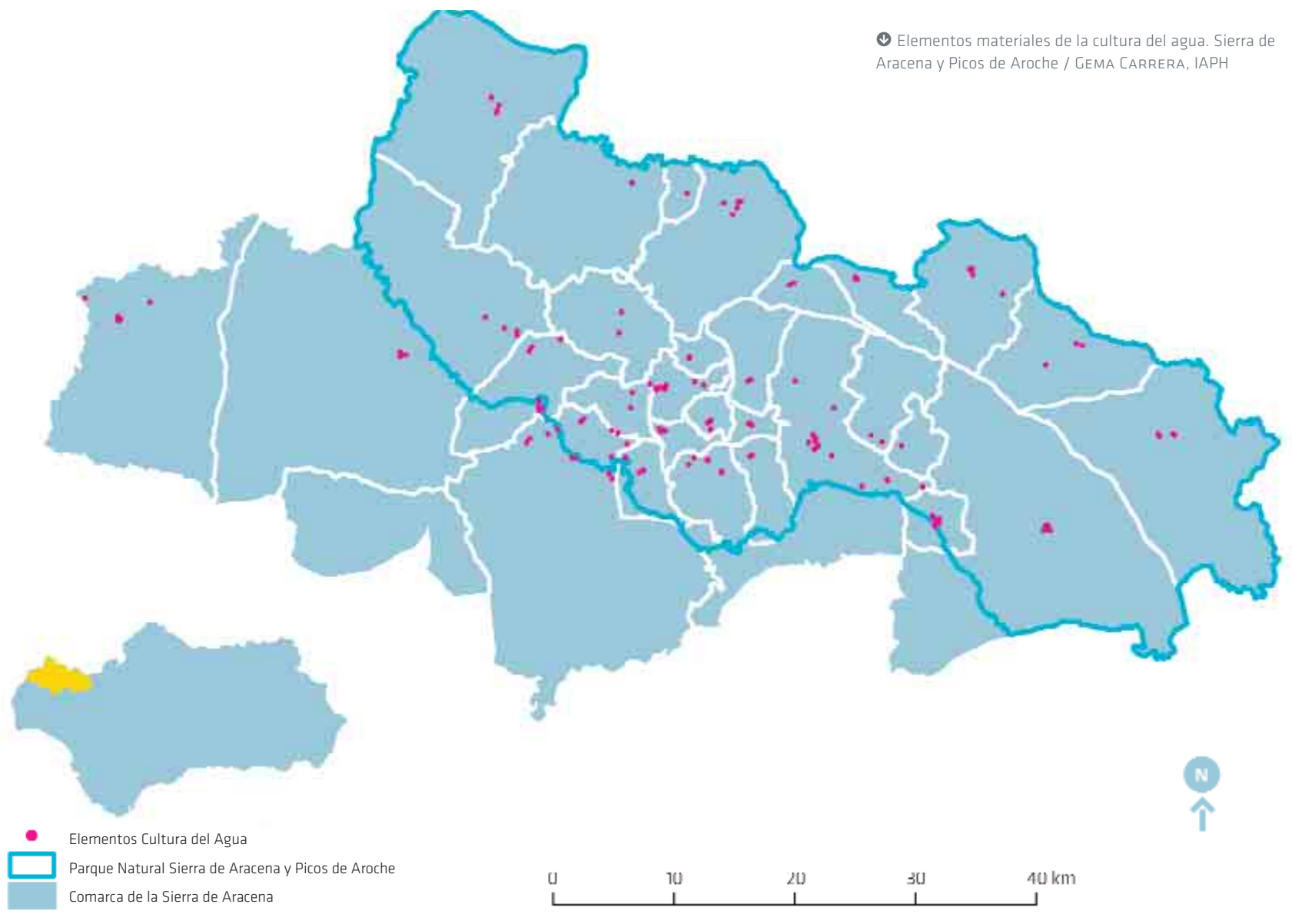

Al igual que el resto de Sierra Morena, la intervención del hombre ha conformado un paisaje donde los aprovechamientos se han adaptado magníficamente a la vocación forestal y ganadera de los suelos y han dado origen a uno de los modelos de explotación mejor integrados ecológica y paisajísticamente en el medio: la dehesa. Por otro lado, la presencia de fuentes y manantiales favorecen el desarrollo de una importante red hidrográfica a la que se asocia uno de los ecosistemas más característico de la comarca, soporte de uno de los recursos paisajísticos con más personalidad: el bosque de ribera. La vegetación potencial del bosque de ribera, hoy muy transformada por la acción antrópica, está constituida por sauces, alisos, chopos, álamos, fresnos y olmos, sustituida en los suelos más ácidos y cursos sin caudal permanente por un matorral aluvial de juncos, adelfas y tamujos, que en los regajos cede paso a la zarzamora y el rosal silvestre. Pueden encontrarse representaciones de este bosque galería en algunos tramos de la Rivera del Múrtiga, la Rivera de Huelva, la Rivera Caliente, el Arroyo Guijarra, la Rivera del Chanza y el Barranco del Colgadizo que se convierten en refugio de fauna rico en biodiversidad.
Son tres las cuencas a las que vierten los cursos de agua de la Sierra, donde tienen origen la mayoría de los ríos de la provincia: la del Guadiana, la del Guadalquivir y, con menor entidad superficial, la del Odiel. Los ríos más representativos son el Múrtiga y el Chanza para la primera, el Rivera de Huelva para la del Guadalquivir y el río Odiel para esta última cuenca. Se trata paradójicamente de una comarca que, pese a que es netamente exportadora de recursos hídricos por su alta pluviometría, apenas los aprovecha, y los recursos regulados en la Cuenca del Guadalquivir por los embalses de Aracena y Zufre abastecen a Sevilla y su área de influencia, mientras que algunas localidades de la comarca no tienen garantizadas el suministro los años secos.

Si bien el agua es un elemento que nos proporciona la naturaleza, el control y el dominio del agua para su propia reproducción ha sido una constante preocupación del hombre y, por tanto, un elemento económico, cultural y social de crucial importancia. Y es que todas las características físicas descritas condicionan, aunque no determinan, las respuestas culturales que se dan en su seno y que ayudan a configurar el paisaje.
El aprovechamiento humano de estos recursos hídricos en la Sierra de Aracena ha tenido una fuerte componente económica, territorialpaisajística, social y simbólica. Económica porque en el control del agua se fundamentan unas determinadas estrategias de producción y reproducción económicas y sociales. La función primordial de fuentes y acuíferos va a ser el abastecimiento con fines domésticos (fuentes, lavaderos), agropecuarios (abrevaderos) e industriales (molinos hidráulicos) ya que el agua ha sido la fuente de energía fundamental de diferentes actividades productivas.

Desde el punto de vista espacial, el agua ha sido crucial en la configuración de la trama urbana y en la ubicación de los núcleos de población. Son los recursos hídricos subterráneos los que explican en buena medida la distribución del poblamiento en la comarca. En efecto, los asentamientos se concentran mayoritariamente en el macizo centro-meridional, donde se localiza uno de los mantos acuíferos de la comarca, origen de abundantes fuentes naturales. En este sector centrosur se ubica una de las dos unidades hidrogeológicas del Parque (la otra, Cañaveral-Santa Olalla, afecta a la franja nordeste): la unidad Galaroza-Zufre, que se extiende de Cortegana a Zufre y de Galaroza-Aracena a Santa 


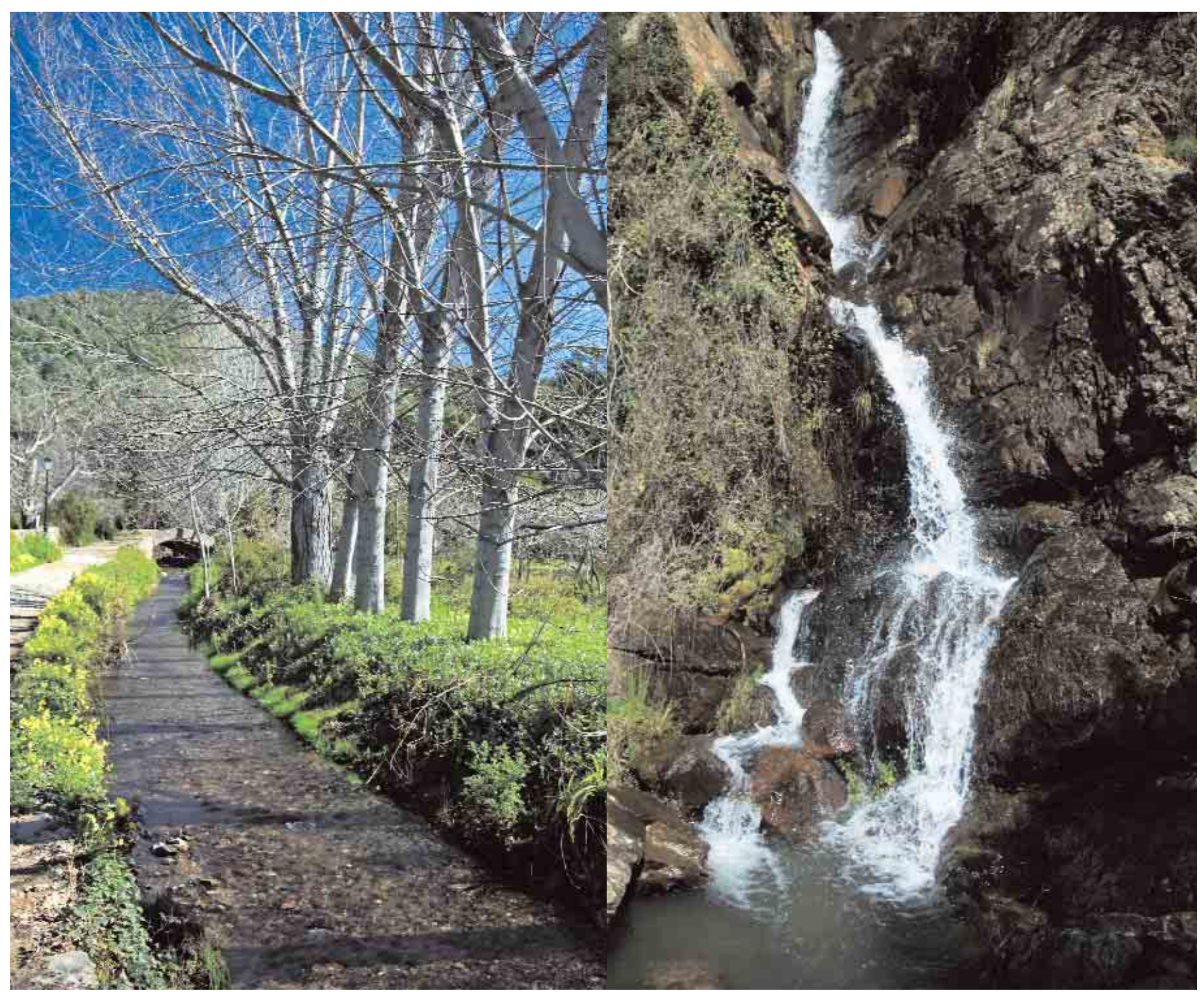

(1) Arroyo de Linares de la Sierra / JAVIER Romero, IAPH

(1) Los Chorros Joyarancón en Santa Ana la Real / JAVIER Romero, IAPH 


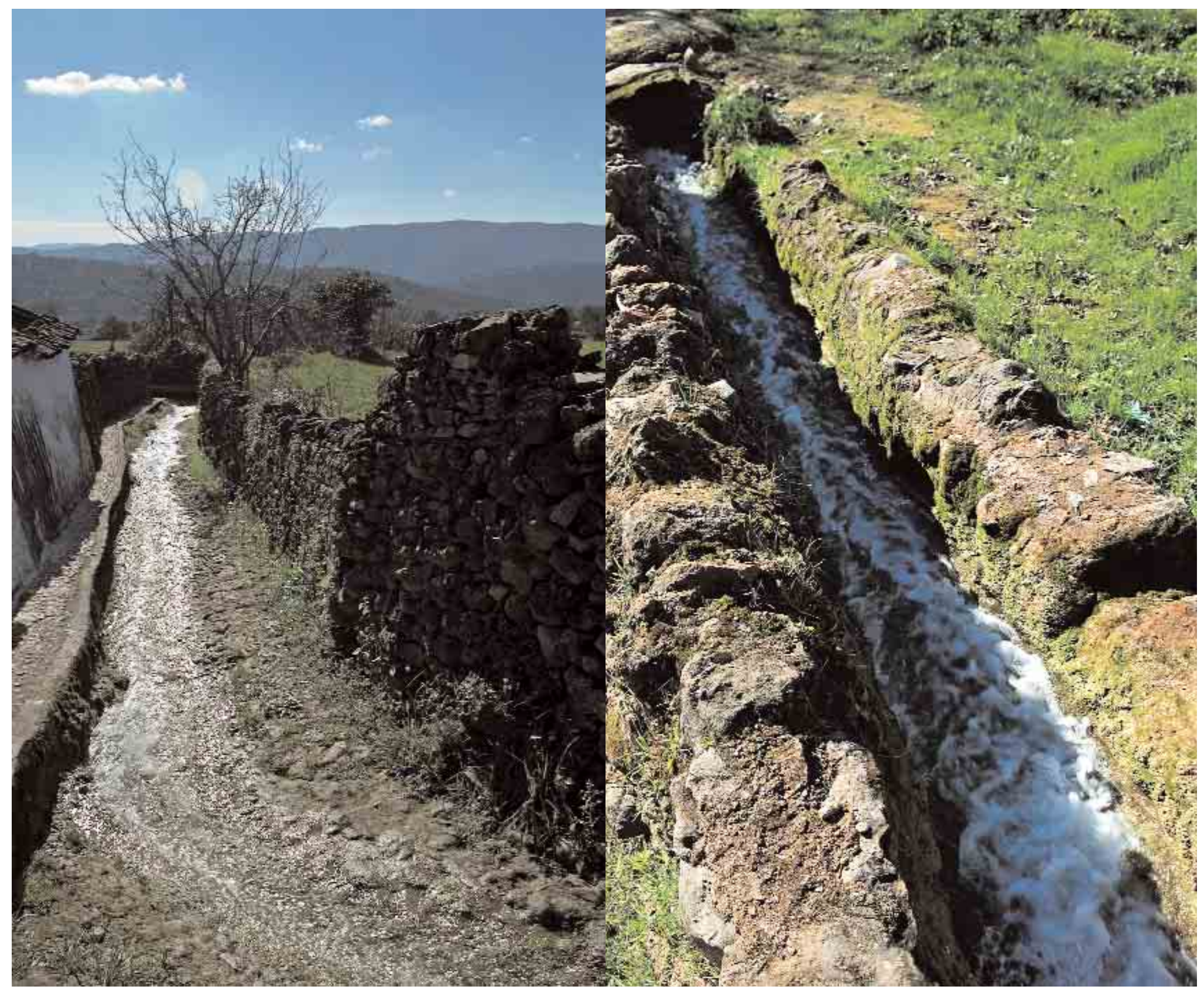

(1) La Calleja del Agua. Cañaveral de León / JAVIer Romero, IAPH

(1) Lieva en Cañaveral de León / JAVIER Romero, IAPH 


\section{Cultura de la necesidad}

En la Sierra de Aracena y Picos de Aroche ha sido, sin duda, la presencia del agua, ligada a la presencia de calizas, mármoles y dolomías (formaciones rocosas que favorecen la existencia de numerosas surgencias y manantiales), la que ha permitido un poblamiento característico, en especial en su zona central, de numerosos pequeños núcleos habitados a muy escasa distancia, diferenciado del dominante en las zonas más orientales de Sierra Morena.

Es en este territorio donde se asienta la Federación de Asociaciones de la Sierra de Huelva que agrupa a más de veinte asociaciones vinculadas a la defensa y difusión del patrimonio natural y cultural de sus pueblos. Su creación, hace ya doce años, tuvo como objetivo principal mejorar la coordinación y la organización de las Jornadas de Patrimonio que se venían celebrando en la comarca desde el año 1985 a iniciativa de unas pocas asociaciones culturales. Estas Jornadas, que cuentan ya con veintidós ediciones, tienen lugar cada año en una localidad diferente, y son organizadas de forma conjunta con su Ayuntamiento, una asociación local y la Federación, contando con el apoyo de la Junta de Andalucía, la Diputación y el Grupo de Desarrollo Rural Sierra de Aracena y Picos de Aroche. Las actas de las jornadas, editadas anualmente, constituyen una herramienta imprescindible para acercarse a conocer el patrimonio de la Sierra.

El agua y el patrimonio que genera, ya sea el dedicado a aprovecharla como recurso natural escaso e imprescindible para la vida o el construido para defenderse de su poder destructivo, patente por contra en momentos de fuertes aguajes, ha sido objeto de atención en numerosas ocasiones. En el primer caso, las fuentes han sido sin duda protagonistas principales, pero también las construcciones ligadas a su extracción (pozos o socavones), a su conducción hacia huertas o molinos (lievas, "regaeras" o acueductos) y a su almacenamiento (albercas, pilares, aljibes o balsas y, en el ámbito más doméstico, lavaderos). En el segundo, las soluciones de la arquitectura popular en la ubicación, orientación o tipología de la casa tradicional serrana, en la construcción de las cercas de pared, extendidas a lo largo y ancho del territorio, o las utilizadas en los caminos para tratar de domesticarla y evitar el daño de las arroyadas salvajes. No se pueden olvidar otros aspectos como su relación con el paisaje, el modelado geológico, el clima o la pluviometría, así como los rituales del agua.

La cultura del agua, sólo un aspecto de la cultura de la necesidad, ha sido secularmente una cuestión de efectividad y eficiencia. La modernidad ha alterado la cultura del agua en la Sierra como en todas partes. El aumento del consumo por cambio en la forma de vivir, el derroche por falta de conciencia de la realidad y la contaminación por incuria, ignorancia y mala fe, han llevado las cosas a un punto que requiere actuaciones extraordinarias. El futuro depende de la planificación de nuevas estructuras adaptadas a la realidad social pero, antes que otra cosa, de la toma de conciencia social de que el agua es un bien escaso y frágil, no sea que, habiendo recibido un mundo sobrio y sostenible, aunque modesto, leguemos a las generaciones futuras unas estructuras de oropel en un espacio inhabitable para un tiempo de penurias.

Vicente Rosselló Olivares

Presidente de la Federación de Asociaciones de la Sierra de Huelva 


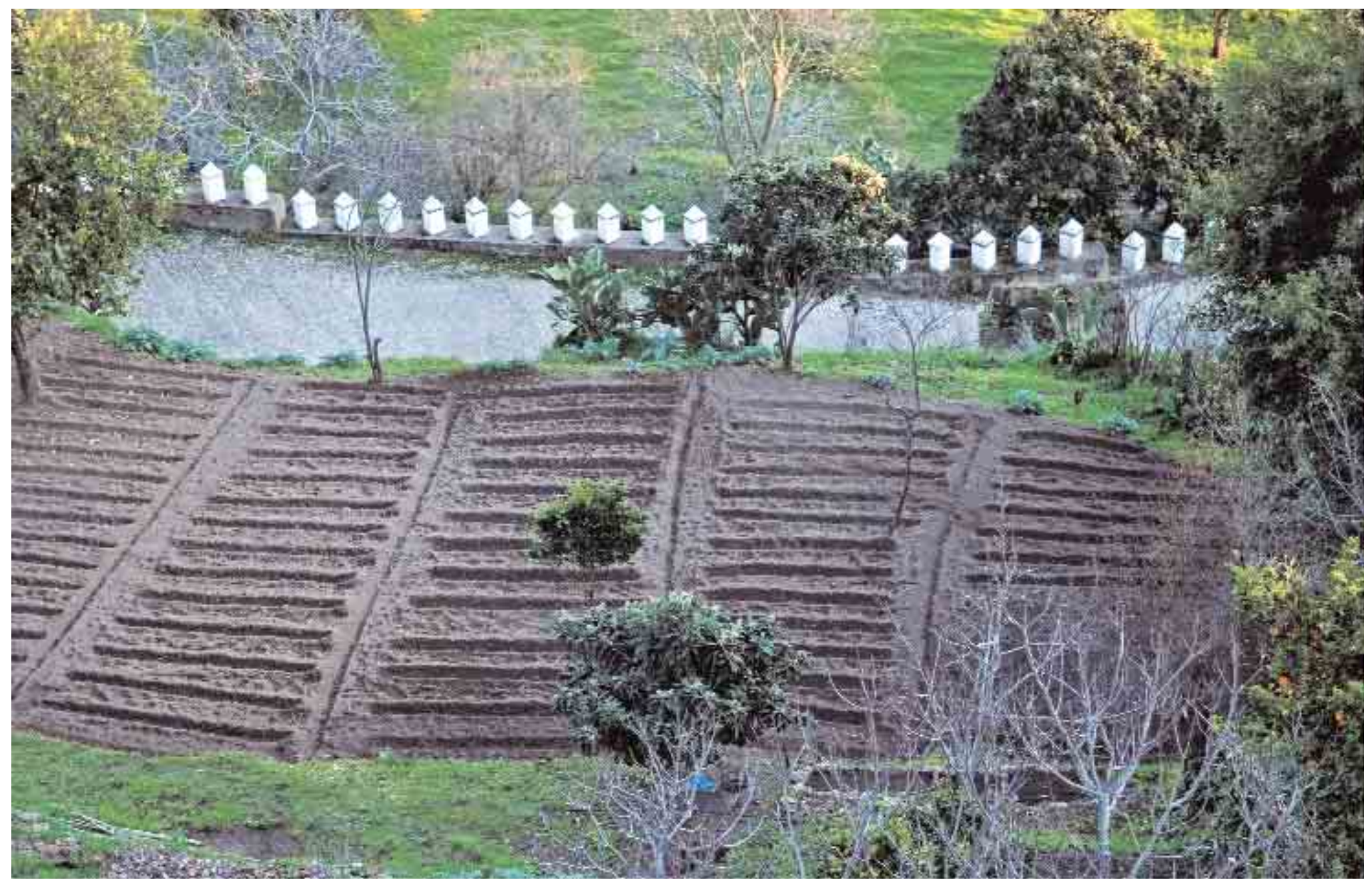

(1) Huertos en Zufre / JAVIer Romero, IAPH

Ana-Linares. Esta franja de terrenos permeables ocupa 127 km² y sus aguas afloran al exterior a través de numerosos manantiales. La abundancia del recurso y la mayor accesibilidad de la zona, menos prolija en valles encajados, explican la concentración de poblaciones y aldeas, y una relativa alta densidad de población en este sector centro-sur.

La necesidad de aprovechar y controlar el agua ha dado como resultado unas características paisajísticas donde naturaleza y cultura se dan la mano y se relacionan de forma tan armoniosa que, a veces, se confunden. La existencia de fuentes y manantiales va asociada a la de sistemas de regadíos de huertos en los ruedos de los pueblos y aldeas. Junto a ellos, en torno a los manantiales, han surgido históricamente un conjunto de fuentes, surtidores, lavaderos, abrevaderos, molinos hidráulicos y otras manifestaciones constructivas vinculadas al uso controlado del agua que constituyen un rico patrimonio cultural relacionado con las formas de vida de la gente de la sierra, dejando su impronta en el paisaje y en la memoria social de sus colectivos.

Las diferencias pluviométricas y de caudal en los cursos de agua van a influir en la distribución, densidad, tipologías y variantes de la arquitectura relacionada con el aprovechamiento del agua en este territorio.

En el caso de los molinos harineros, que en la sierra son siempre hidráulicos, las características orográficas y climáticas de la zona constituyen, entre otros, uno de los factores que más influye en la presencia, distribución y formas que adquieren a lo largo de la comarca. La alta pluviosidad permitía mantener un gran número de molinos en funcionamiento para abastecer una necesidad primordial de la población: el consumo de pan. La existencia de molinos es mayor en las zonas donde existe un río importante o con caudal continuo, como son los antes citados: a occidente, el Múrtigas o el Chanza; al Norte, la Rivera de Huelva y, hacia el Sur, el río Odiel. Este hecho condiciona no sólo la presencia de molinos, sino también la 


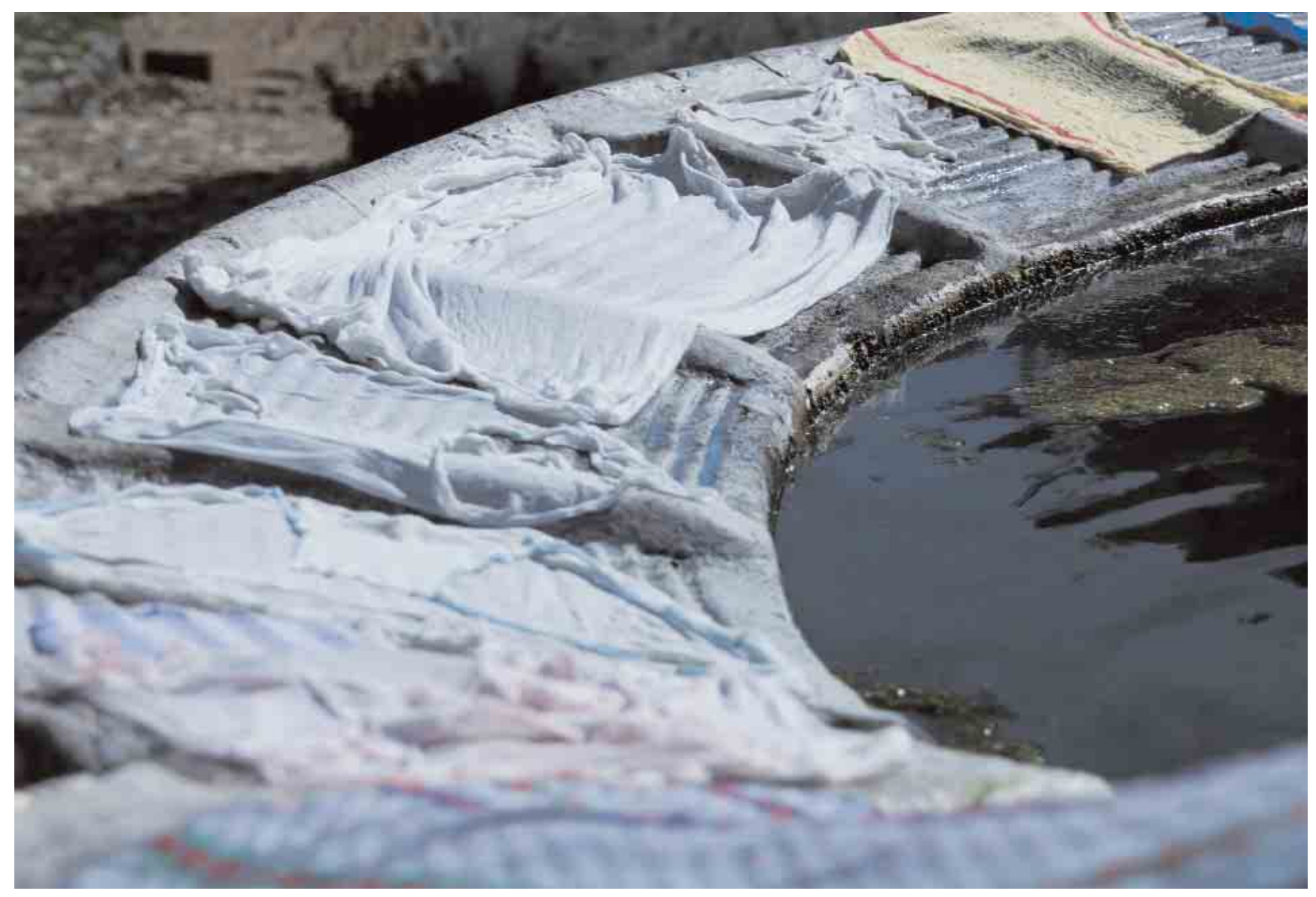

(1) Lavadero de la Fuente Nueva. Linares de la Sierra / GEMA CARRERA, IAPH

Fuentes, lavaderos, abrevaderos, molinos

hidráulicos y otras

construcciones

vinculadas al uso del

agua constituyen un

rico patrimonio cultural manera de conducir y aprovechar la fuerza del agua. La fuerza de la intervención humana es inversamente proporcional a la fuerza del caudal del agua. En las zonas con arroyos menores serán más complejas las construcciones (longitud de las acequias; forma y magnitud de los cubos -con alcoba o sin ella-; presencia o no de represas; sistema de molienda - a hilo si el caudal es grande, a represa si el caudal es escaso; separación o no entre la sala del molino y vivienda del molinero, etc.) (MUÑIZ CARRASCO, 1996). Todo ello influirá en la enorme variedad de molinos que se dan en la zona como resultado de la relación entre las características hidrográficas de la comarca y las respuestas culturales a dichas condiciones.

Sin lugar a dudas, la fuente, sencilla o monumental, muchas veces unida a lavaderos y/o abrevaderos, es otro de los elementos que materializan la relación agua, naturaleza y cultura en la Sierra de Aracena. Parafraseando al profesor Medianero (MEDIANERO HERNÁNDEZ, 2003), la fuente es una síntesis entre un conjunto de realidades: una realidad física, un dato geológico, un lugar de abastecimiento, un recurso económico, un espacio de sociabilidad, una obra y una construcción, un topónimo y una referencia nominal, un testimonio histórico, un alarde político, un hito emblemático, un gestador de leyendas, es lugar central en los rituales festivos, es lugar sagrado y de santificación, es venero con propiedades curativas, es reclamo turístico. En definitiva, independientemente de la forma que adquiera, muchas y muy variadas en la Sierra (consúltese el trabajo de J. M. Sánchez en la p. 72), lo que sí es común a todas ellas es que se trata de un producto del hombre que aprovecha colectivamente un recurso natural para cubrir necesidades de la vida doméstica en el ámbito público (lavadero y abastecimiento humano o del ganado). Más allá de su función primordial como abastecedoras de un bien necesario para muchos aspectos de la vida humana, las fuentes tienen un valor simbólico importantísimo como lugares de relación social, como enclaves de convivencia y lugar de encuentro, constituyendo verdaderas ágoras serranas de trabajo y de sociabilidad, ya sean de ámbito femenino (lavaderos), o masculinos (abrevaderos), o de la relación entre ambos. 


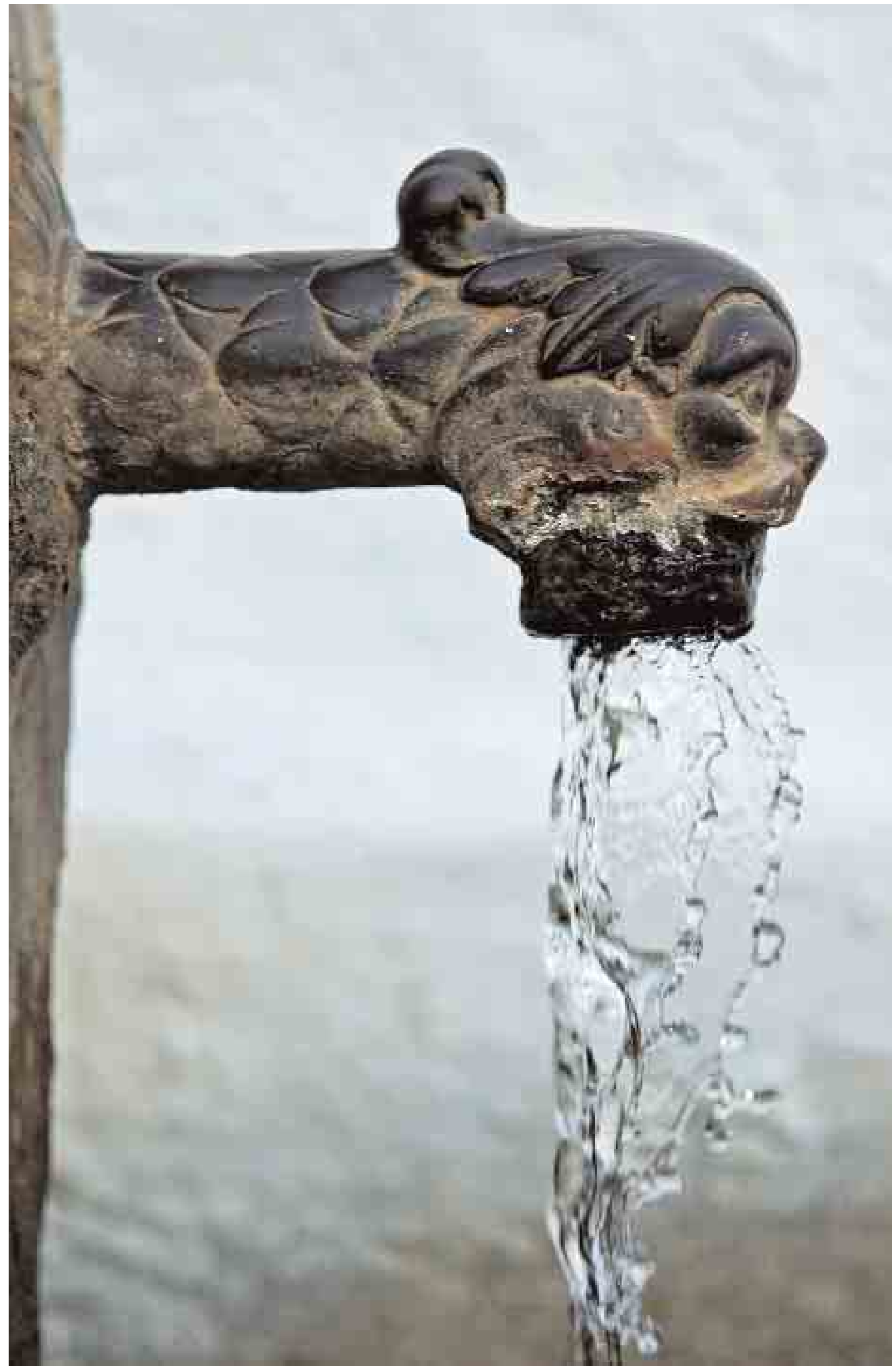

(1) Detalle del surtidor de la Fuente de los Doce Caños en Galaroza / JAVIER RomERo, IAPH 